\title{
Patient perspectives on delays in cervical cancer screening and follow-up care in Botswana: a mixed methods study
}

\section{Surbhi Grover ( $\nabla$ Surbhi.Grover@pennmedicine.upenn.edu )}

University of Pennsylvania Perelman School of Medicine

Katharine A. Rendle

University of Pennsylvania Perelman School of Medicine

Doreen Ramogola-Masire

University of Botswana

\section{Barati Monare}

Botswana-University of Pennsylvania Partnership

\section{Shannon Ogden}

Boston University School of Public Health

\section{Hannah Toneff}

University of Pennsylvania Perelman School of Medicine

Chelsea Saia

University of Pennsylvania Perelman School of Medicine Jocelyn Wainwright

University of Pennsylvania Perelman School of Medicine

Tara Friebel-Klingner

University of Pennsylvania Perelman School of Medicine

Natalie Bonner

UT Southwestern Medical School

Lisa Bazzett-Matabele

University of Botswana

\section{Tlotlo B Ralefala}

Princess Marina Hospital, Department of Oncology

\section{Rohini Bhatia}

Johns Hopkins Medicine

Rebecca Luckett

Beth Israel Deaconess Medical Center

\section{Peter Vuylsteke}

University of Botswana, Department of Internal Medicine 


\section{Research Article}

Keywords: Public health, Screening, Cancer, HIV, Qualitative Study

Posted Date: February 28th, 2022

DOI: https://doi.org/10.21203/rs.3.rs-1346846/v1

License: (c) (i) This work is licensed under a Creative Commons Attribution 4.0 International License. Read Full License 


\section{Abstract}

Background: Delays in screening and timely diagnosis contribute significantly to global disparities in cervical cancer mortality in Botswana and other low- and middle-income countries, particularly those with high rates of HIV. Little is known about the modifiable factors shaping these delays from the perspectives of women themselves.

Methods: From March-May 2019, we conducted a concurrent, mixed methods study of patients receiving cervical cancer care in Botswana. Structured questionnaires captured beliefs and knowledge related to cervical cancer screening and HIV. Clinical data were abstracted from medical records and confirmed by participants. Semi-structured interviews examined patients' understanding of and experiences with cervical cancer screening. Quantitative data were analyzed using descriptive and bivariate statistics. Qualitative data were analyzed using deductive and inductive content analysis and triangulated with quantitative data to identify areas of convergence and divergence.

Results: Forty-two women were interviewed, $64 \%$ of whom were living with HIV. Median age was 45 years in women living with HIV (LWH) and 64 years in those without HIV. Overall screening rates prior to symptomatic disease were low (24\%). Median time from most proximal screening to diagnosis was 52 median days (IQR: 15-176), with no significant differences by HIV status. General screening knowledge was higher among women living with HIV versus those without (100\% vs $73 \%$ ), but knowledge about specific risk factors including HPV was low in both groups. In interviews, participants expressed limited awareness of needing to be screened prior to symptoms. Additionally, participants reported significant delays in receipt of screening results and in obtaining referrals for follow-up care. However, participants also described myriad sources of social and tangible support that helped them to overcome some of these challenges.

Conclusion: Interventions focused on increasing routine screening and supporting timely awareness and access to care are needed to reduce global disparities in cervical cancer.

\section{Background}

Cervical cancer is the fourth leading cause of cancer mortality in females globally with over 600,000 new cases and 300,000 deaths estimated in 2020 alone.(1) The vast majority (approximately 90\%) of cervical cancer cases and deaths occur in low- and middle-income countries (LMICs), particularly those with high rates of HIV as cervical cancer is an AIDS-defining malignancy.(1) Botswana is burdened with high rates of cervical cancer incidence (34.4 per 100,000) and mortality $\left(20.1\right.$ per 100,000) and HIV $(18.5 \%){ }^{1}$ Despite a robust HIV care infrastructure and a national program in cervical cancer screening, ${ }^{2-4}$ the majority of patients with cervical cancer in Botswana present with locally advanced disease, driven partly by suboptimal implementation and delays in evidence-based care across the cancer control continuum. ${ }^{5}$ ${ }^{6}$ This is particularly concerning given that cervical cancer is considered to be nearly completely preventable and often curable if treated early. ${ }^{67}$ 
In high-income countries, cervical cancer screening and timely access to treatment has dramatically reduced incidence and mortality from this preventable and curable disease. $(2,3)$ While screening coverage in high income countries is around 63\%, screening coverage in LMICs averages $19 \%$.

(4) Previous research in LMICs have identified a number of challenges to successful implementation of cervical cancer screening programs including limited resources for pathology with resulting delays in receipt of results and limited access to treatment, both of which contribute to advanced disease at diagnosis and disease progression prior to treatment. $(5,6)$ Despite significant progress and investment in HIV treatment and cervical cancer screening programs in Botswana both by the Government of Botswana and donors, incidence of cervical cancer remains very high. $(7,8)$ Most cervical cancer patients present at advanced stages and about half of the women with cervical cancer report that they have never been screened for cervical cancer.(8-10) While previously published literature points to lack of cervical cancer awareness among women in Botswana, little is known about how individual, community, or system-level factors shape delays across screening and diagnostic pathways from the perspective of women themselves or how delays may be amplified or attenuated for women living with HIV. $(11,12)$

Our study was conducted to gain deeper understanding into the persistence of high rates of advanced stage of cervical cancer at presentation and mortality despite increased efforts towards cervical cancer screening and diagnostic follow-up. Here we describe and compare patient-reported facilitators and barriers to timely screening of cervical cancer among women living with and without HIV who were diagnosed with cervical cancer in Botswana.

\section{Methods}

The goal of this mixed methods study was to understand patient-reported factors shaping delays in cervical cancer screening and follow-up among patients presenting for cervical cancer care. Participants interviewed in this study were part of a larger clinical cohort study of nearly 2,000 patients designed to quantify delays in cancer care and outcomes of cervical cancer patients with cervical cancer. In this substudy, we conducted semi-structured interviews with a subset of patients to examine how individual, community, clinic, and system-level factors shaped delays in screening prior to cancer diagnosis (appraisal, help-seeking, and diagnostic phases) and compared experiences among women living with HIV and without HIV.

\section{Setting}

Recruitment and interviews took place at a public gynecological multidisciplinary team (MDT) clinic in Botswana that provides free cancer care for patients. This clinic is the only one of its kind in the country and sees an estimated $85 \%$ of all patients with cervical cancer patients in Botswana.(9) Most cervical cancer patients present with locally advanced disease warranting radiation. Despite an estimated population of 2 million, Botswana has a single radiation oncology facility with one linear accelerator and one brachytherapy unit, located near the recruiting clinic. Prior to starting treatment, patients with 
histologically confirmed cervical cancer are referred to the MDT clinic, which manages care prior to and after treatment.

\section{Eligibility and Recruitment}

From March-May 2019, we approached potentially eligible patients attending the weekly gynecological MDT Clinic at PMH. Patients do not have scheduled appointments but are rather seen based on when they arrive; thus, many women come early and wait in the designated waiting room. As is customary to this setting, the clinic usually begins with a short hymn and prayer followed by discussion of any cancerrelated topics, led by the clinical research manager (MM). During this discussion, the research coordinator introduced the study and reviewed the charts for eligibility for any women who expressed interest in being interviewed. Patients who were eligible were given an informational consent statement about the study. For patients who verbally agreed to participate, they were interviewed that day in a private room in the clinic. All study activities were approved by the institutional review boards at University of Pennsylvania, $\mathrm{PMH}$, and Ministry of Health and Wellness of the Republic of Botswana prior to study conduct.

\section{Data Collection}

After receiving written informed consent, a research team member (clinical study coordinator) who has experience conducting interviews in Setswana and English administered the interviews in the participants' preferred language. Following approximately five interviews, an expert in mixed methods research (KR), reviewed the transcripts and provided feedback to help refine the interview process and content. The interview guide included both structured survey questions and open-ended questions. Data collection consisted of an orally administered structured quantitative survey and an audio-recorded semi-structured qualitative interview. Interviews lasted approximately 30 minutes on average and were professionally transcribed and back-translated to English for analysis.

\section{Quantitative Measures_}

The structured questionnaire captured participant sociodemographic information (e.g., education, marital status, number of children, cell phone ownership, place of residence), and assessed beliefs and knowledge related to cervical cancer risk, screening, and HIV. Drawing upon similar studies conducted in sub-Saharan Africa, we used survey items to measure general cervical cancer screening awareness, human papillomavirus (HPV) and cervical cancer screening knowledge, and experiences of HIV and cervical cancer screening stigma.(13) General cervical cancer screening awareness (e.g., "Have you ever heard of cervical cancer?" and "Have you ever heard of HPV or human papillomavirus?") were measured using seven items with either a "Yes," "No," or "No Response." HPV and cervical cancer screening knowledge was measured by 15 statements to which the participants responded as "True," "False," or "I don't know." Some example statements included, "Women should get screened for cervical cancer only if 
they have symptoms," "Having HIV increases a woman's risk of cervical cancer," and "HPV is an infection that can cause cervical cancer." Experiences of HIV and cervical cancer screening stigma (e.g., "Do you feel you were rejected by family?" and "Did you become a social outcast?") were captured separately by the same eight items with responses of "Yes," "No," or "No Response."(13) Additional clinical data was abstracted from medical records regarding clinical factors, such as stage, pathology, screening history, and treatment dates.

For the assessment of general HIV awareness, and HIV transmission and prevention knowledge, we used items from a prior survey conducted among adults in Botswana.(14) All of these items had "Yes," "No," or "I don't know" response options. Table 2 includes language items includes in analysis.

\section{Qualitative Interview}

Guided by the domains across the Model of Pathways to Treatment, the semi-structured qualitative interview consisted of open-ended questions designed to gather additional insights on participants understanding of cervical cancer screening, HPV, and HIV and to capture experiences with cervical cancer screening and follow-up care. The interview guide consisted of questions related to 1) knowledge of cervical cancer, cervical cancer screening, HPV, and HIV; 2) decision-making factors in regard to cervical cancer screening and treatment receipt; 3) cervical cancer diagnosis and treatment experiences; and 4) health information and care seeking behaviors.(8) The semi-structured guide was systematically used to interview all participants, allowing for consistent interrogation of domains across and within participants. In this manuscript, we focus on the experiences up to cancer diagnosis.

\section{Mixed Methods Data Analysis}

For quantitative analysis, we used descriptive and bivariate statistics to summarize the quantitative data from the structured surveys across all participants and to compare any differences by HIV status. To calculate delays in care, we used clinical data on prior screening dates, biopsy dates, and treatment dates. Differences by HIV status were examined using Fisher's exact test for categorical variables and Student t-tests for continuous variables. All statistical analyses were conducted using STATA 15, and pvalues $<0.05$ were considered statistically significant.

For the qualitative analysis, we employed a combination of deductive and inductive approaches to content analysis. ${ }^{9}$ (15) First, the researchers were guided by the Model of Pathways to Treatment to capture patient, community, clinical and system-level factors contributing to the delays to cervical cancer screening during each phase of the decisional and behavioral processes prior to beginning treatment (appraisal, help-seeking, diagnostic phases).(16) Then, we utilized modified grounded theory to identify additional concepts in the data, such as perspectives on health and healthcare generally.(17) Throughout the coding stages, the team developed and refined a codebook to apply specific codes to the data that aligned with the various decisional and behavioral factors around cervical cancer screening and 
diagnostic care. The codebook finalization and analysis underwent an iterative process where the research team conferred and agreed upon the code definitions and resulting themes. We triangulated qualitative themes and quantitative survey data to identify areas of convergence and divergence.(15)

\section{Patient and public involvement}

Outside of the participation of local clinical stakeholders in Botswana and study participants, there was no patient or public involvement in this study.

\section{Results}

\section{Patient Characteristics}

We interviewed 42 women undergoing cervical cancer treatment of which $64 \%$ were living with HIV at the time of diagnosis (Table 1). Median age was significantly lower $(\mathrm{p}<0.001)$ in women living with HIV (45 years) compared to those without HIV (64 years). Women with HIV were more likely to present with earlier stage of disease compared to women without HIV, with $47 \%$ of women living with HIV presenting with Stage III in comparison to $15 \%$ of women living without HIV ( $p=0.01)$. Most women interviewed had a primary education level or lower (40\%), identified as Christian (90\%), and preferred Setswana as their primary language (83\%). In comparison to women living without HIV, women living with HIV were more likely to use public transportation ( $96 \%$ vs $80 \%$ ) and more likely to be single ( $85 \%$ vs $53 \%$ ) at the time of the interview.

Overall screening rates were low among participants regardless of their HIV status; only $24 \%$ reported to ever being screened prior to developing symptoms. At the screening visit most proximal to cancer diagnosis, $60 \%$ of participants had symptoms (Table 1). Across participants, it took median 52 days (IQR: 15-176) from their most proximal screen to receipt of cancer diagnosis, with no significant differences by HIV status.

General awareness and knowledge regarding cervical cancer screening was high in both groups, but knowledge about specific risk factors including HPV was low. Only $62 \%$ of women knew HPV can cause cervical cancer and only 5\% knew that HPV infection can be asymptomatic. In comparison to women living with HIV, women living without HIV were significantly less likely to know that women should be screened even if there are no symptoms $(100 \%$ vs. $73 \%$, p-value $=0.01)$. Regarding specific risk factors, women living with HIV tended to report higher levels of screening knowledge in comparison to women living without HIV overall (Mean (0-12): 8.9 vs 10.0, p-value=0.05), with only one item reaching statistical significance. Women living with HIV were more significantly more likely to know that vaginal washing $(67 \%$ vs $27 \%$; $p=0.01)$ did not increase cervical cancer risk than their counterparts. Table 2 outlines all survey measures overall and by HIV status. 


\section{Exploring Experiences and Drivers of Delay: Appraisal, Help- Seeking, and Diagnostic Phases}

Across the initial three phases of the Model of Pathways to Treatment (Appraisal, Help-Seeking, and Diagnostic Phases), patients reported a variety of individual, community, and system-level factors that both hindered and enhanced access to timely care. Table 3 outlines thematic quotes from various phases in Model of Pathways to Treatment in addition to the sections below.

\section{Appraisal: Screening Awareness and Symptom Assessment}

In line with quantitative findings, many participants expressed limited awareness of risk factors that can contribute to cervical cancer, particularly HPV, throughout the interviews. This is exemplified in the response of one participant who stated "Honestly, I cannot talk about HPV because it is the first time I hear the name HPV, and this is what would make it difficult for me to answer." (Early-50s, Person Living with HIV (PLWH))

Similarly, few participants knew that cervical cancer could be prevented through screening and thus often described screening as a test to find out if they have cancer or if they were experiencing symptoms, as reflected by these two participants:

"I have not heard of anything that causes cervical cancer. I do not know how it can be prevented but I heard people mentioning that for one to know if they have cervical cancer, they have to go for cancer screening." (Early-40s, PLWH)

"I once heard that when experiencing a lot of unpleasant vaginal discharge, one should check the doctors for cervical cancer screening." (Late-50s, PLWH)

One participant further explained that she was unaware of the potential severity of cervical cancer, "Now I know the danger of cervical cancer. Back then I did not know. When people talked about cancer and its existence, I never paid attention. I did not know anything." (Late 40s, PLWH).

\section{Help-Seeking: Undergoing Screening and Diagnostic Evaluation}

Many participants expressed individual fears or concerns as barriers to screening and cancer care including fear of going to the hospital. For many women, like these two participants, this fear stemmed from both general avoidance of care and concerns of treatment itself. 
"I would often, in my life like I was telling you that I am not someone who visits hospitals regularly, hear people speaking ill of [the local hospital]. As if to say when you go to [this hospital] you are lost." (Late60s)

"Sometimes we tend to brush off some issues. We delay [screening] and only become alert when the signs start showing." (Late-50s, PLWH)

In addition to individual fears, structural factors including limited testing equipment and other resources, added to challenges in screening and diagnosis as noted by this participant.

"I once went to the clinic and for us with HIV. We are supposed to have tested for cervical cancer before seeing a doctor. I went there and when it was my turn we were told that there was no testing equipment... The resources should always be available especially for patients living with HIV because we are too vulnerable to some illnesses." (Early-40s, PLWH)

\section{Diagnosis: Receiving Results and Follow-up Care}

Across the participants, the most substantial driver of delays seemed to be delays in both receipt of screening results and delays in appointments following abnormal screening.

Timeliness of return of screening results to patients varied widely. Many participants stated that they did not receive the results at all, even after multiple screenings. As one woman expressed when explaining why she eventually stopped going to get screened: "I once screened when I went for a six-week ante-natal checkup in [other city]. I always tested but did not receive any results until I gave up." (Early-40s, PLWH)

Women also reported delays in returning for appointments following abnormal screening, even though they were recommended.

"The [screening] results were not good [in 2016]. I am the one who delayed to go to the doctor... [until 2018 when] I went back to the nurse to say, 'I have not taken any measures since."' (Early-50s, PLWH)

\section{Cross-Cutting Facilitators}

Amid discussions of the various challenges that women faced, many women described sources of support and strength that helped them to overcome these challenges. Several women noted that they drew upon their community including their children and their religious community if they were in need. For example, one woman stated,

"I could not accept the results very well, it was so difficult, my children sat me down and explained that cancer is like any other disease, and I could live longer if I go for checkups regularly." (Late-50s, PLWH) 
Other women noted that system-level or community services are available and they can easily access them if they seek them out.

"It is not difficult [to seek healthcare services] because some of us know the illnesses we have and where to go for assistance at the clinic. When you are given something to take for your ailment you also know what to do... It is easy because I have already taken a step towards it. I have not hidden my medical condition." (Early-50s, PLWH)

\section{Discussion}

This study provides insight on patient-reported factors shaping delays in timely screening among women with cervical cancer in Botswana. Only $24 \%$ of women reporting ever being screened prior to presenting with symptomatic disease. While other clinic-based studies in Botswana have indicated higher rates of screening, our results indicate that many women diagnosed with cervical cancer are not undergoing screening prior to cancer diagnosis, which is a missed opportunity to increase early detection and improve survival.(11) Although Botswana implemented a national screening program in 2012 and there have been concerted efforts to integrate cervical cancer screening into HIV care, our results indicate that screening remains suboptimal even for women who are receiving HIV care.(7) Screening prevalence are generally lower in sub-Saharan Africa. Two population-based surveys have reported screening prevalence rates for sub-Saharan countries (16.9 and $19.0 \%$ ), with even lower rates of $4.8 \%$ and $6 \%$ in some countryspecific reports.(18-22)

Our qualitative analysis showed that various challenges exist in the screening journey for women in Botswana. Amid the numerous barriers, participants also noted different sources of both social and structural support that helped to mitigate or at least reduce the burden of care for some women.

Individual factors such fear of cancer, limited awareness of treatment options, and system-level delays such as delays in results contribute to those challenges. Fear of cancer as a barrier to screening in subSaharan Africa has been reported by several authors, specifically as most women consider cancer to have no treatment. $(23,24)$ These women also reported fear or embarrassment of undergoing the screening test itself, and abandonment after a cancer diagnosis. Judgmental attitudes by health care providers have also been reported as a contributing factor to this fear.(25) System-level delays are a common occurrence in sub-Saharan Africa which leads to delays in treatment initiation as well as a deterrent for utilizing screening services. $(24,25)$

In comparison to studies in the general population in Africa, we observed high rates of cervical cancer knowledge, which has also been noted in other studies looking at awareness of cervical cancer screening in Botswana. $(11,26)$ Furthermore, women included in our study have undergone treatment for cervical cancer already and likely discussed screening and risk factors in greater detail than women who have not been diagnosed with cancer. However, despite being diagnosed with cervical cancer, knowledge regarding HPV as a risk factor was low. Poor knowledge of HPV as a risk factor for cervical cancer has also been reported by other authors in the region.(27) In the interviews, women often stressed that needing to be 
tested to find out if one had a cancer, potentially influenced by knowledge of HIV transmission. A targeted campaign focused on increasing awareness of HPV as the cause of cervical cancer, but not as a cancer diagnosis itself, may help to enhance both knowledge and also reduce potential fear of the test itself.

As indicated by other studies, women living with HIV had higher levels of screening knowledge. $(11,28)$ We observed differences in both the qualitative and quantitative data in our study, with women living with HIV generally having greater screening knowledge potentially due to their established connection to healthcare systems and clinics. In contrast to higher income countries, like the US, where delays are greater in those women living with HIV, in Botswana being integrated into the HIV care infrastructure may enable greater awareness and access to preventive care. However, as indicated by our results and the results of others, these differences in knowledge and awareness do not transfer to differences in delays as all women face substantial delays in diagnosis confirmation $(29,30)$. Furthermore, despite the enhanced focus on screening for women connected to HIV care, there is still a great need to increase screening in the higher risk population.

Given the myriad of factors driving delays in screening and follow-up in Botswana, there is great need to identify multifactorial approaches to support patient-level barriers while improving system-level processes to care coordination and communication. These efforts could include providing infrastructure for pathology labs to increase communication to referring clinics and to patients, or providing direct navigation for patients who have abnormal results. Additionally, the high levels of knowledge regarding HIV indicate that public campaigns about HIV are working well, and potentially could be an effective model to increase awareness about the important of cervical cancer screening as prevention at an early age. The significance difference in age between women living with HIV and those without is substantial, and similar to other larger scale estimates. Our results indicate that while there is growing infrastructure for both HIV and cervical cancer care, more is needed to ensure women undergo regular cervical cancer screening and if diagnosed, receive their results and care in a timely manner.

\section{Limitations}

In addition to its strengths, this study has limitations including potential recall bias given the timing of these interviews after diagnosis and selection bias given that we conducted the study in the context of a treatment clinic. Furthermore, while the use of in-depth interview provides rich details on the experiences of women undergoing cervical cancer treatment that is often missing from larger studies, this method is not designed to evaluate generalizability of these experiences in the wider population and therefore this study cannot assess how experiences may differ across Botswana or other LMICs.

\section{Conclusions}

Our results indicate that at each phase (appraisal, help-seeking, and diagnosis), patients faced a series of barriers to cervical cancer screening and diagnosis. For cancer screening to be most effective, appraisal requires awareness and knowledge that screening is needed as part of preventive care. Most women, 
even those living with HIV, were symptomatic at the time of screening and described limited awareness that screening should be done when a woman is asymptomatic. This is in direct contrast to relatively high levels of HIV-related knowledge. Related, is limited awareness that HPV, the primary cause of cervical cancer, can be detected through screening before cancer has developed and thus can be prevented.

Beyond appraisal, individual fears of cancer treatment added additional barriers to receiving screening and beginning treatment. Even for those women who had been screened, substantial delays in receipt of positive results remained, contributing further to diagnostic delays and uncertainties about the benefit of screening. Given the multitude of drivers of delays, there is great need for both individual and systemlevel approaches to increasing awareness and timely receipt of screening and follow-up care, without which cervical cancer incidence and mortality will continue to be high in Botswana and other high-HIV prevalent LMICs countries.

\section{Declarations}

\section{Ethics approval and consent to participate}

Patients who were eligible were given an informational consent statement about the study and written informed consent to participate was obtained. All study activities were approved by the institutional review boards at University of Pennsylvania (approval number: 832278), PMH (approval number: PMH 5/79(177-1-2020), and Ministry of Health and Wellness of the Republic of Botswana (approval number: HPDME 13/18/1) prior to study conduct. All methods were carried out in accordance with the relevant guidelines and regulations.

\section{Consent for publication}

Not applicable.

\section{Availability of data and materials}

Restrictions apply to the availability of data used in this study due to consent processes and ethical challenges in truly de-identifying qualitative data. However, summary data may be available from corresponding author upon reasonable request and as allowable by regulatory processes.

\section{Competing interests}

The authors declare that they have no competing interests.

\section{Funding}


This research is supported by a pilot grant from the Penn Center for AIDS Research (CFAR), an NIHfunded program (P30 Al 045008). SG is supported by a training grant from the National Cancer Institute (K08CA230170). SO is supported by a training grant from the National Institute on Drug Abuse (T32DA041898).

\section{Authors' contributions}

KAR and SG jointly led the conception, design, analysis, and interpretation of the data and acquired funding to support the work. DR contributed to the design, analysis, and interpretation of the data. BM, SO, HT, CS, JW, TF, RB, and NB contributed to the collection, analysis, and interpretation of the data and preparation of the manuscript. $\mathrm{LB}, \mathrm{PV}$, and $\mathrm{RL}$ contributed to the collection and interpretation of the data and preparation of the manuscript. All authors contributed to the writing of the manuscript and read and approved the final manuscript.

\section{Acknowledgements}

We are grateful to the research and administrative staff of the Botswana-UPenn Partnership and all participants who made this work possible.

\section{References}

1. Sung H, Ferlay J, Siegel RL, Laversanne M, Soerjomataram I, Jemal A, et al. Global Cancer Statistics 2020: GLOBOCAN Estimates of Incidence and Mortality Worldwide for 36 Cancers in 185 Countries. CA Cancer J Clin. 2021;71(3):209-49.

2. Kulasingam SL, Havrilesky L, Ghebre R, Myers ER. Screening for Cervical Cancer: A Decision Analysis for the US Preventive Services Task Force. U.S. Preventive Services Task Force Evidence Syntheses, formerly Systematic Evidence Reviews. Rockville (MD)2011.

3. Forman D, de Martel C, Lacey CJ, Soerjomataram I, Lortet-Tieulent J, Bruni L, et al. Global burden of human papillomavirus and related diseases. Vaccine. 2012;30 Suppl 5:F12-23.

4. Kawonga M, Fonn S. Achieving effective cervical screening coverage in South Africa through human resources and health systems development. Reprod Health Matters. 2008;16(32):32-40.

5. Sankaranarayanan R, Budukh AM, Rajkumar R. Effective screening programmes for cervical cancer in low- and middle-income developing countries. Bull World Health Organ. 2001;79(10):954-62.

6. Holschneider $\mathrm{CH}$, Ghosh K, Montz FJ. See-and-treat in the management of high-grade squamous intraepithelial lesions of the cervix: a resource utilization analysis. Obstet Gynecol. 1999;94(3):37785.

7. Grover S, Raesima M, Bvochora-Nsingo M, Chiyapo SP, Balang D, Tapela N, et al. Cervical Cancer in Botswana: Current State and Future Steps for Screening and Treatment Programs. Front Oncol. 2015;5:239. 
8. Grover S, Bvochora-Nsingo M, Yeager A, Chiyapo S, Bhatia R, MacDuffie E, et al. Impact of Human Immunodeficiency Virus Infection on Survival and Acute Toxicities From Chemoradiation Therapy for Cervical Cancer Patients in a Limited-Resource Setting. Int J Radiat Oncol Biol Phys. 2018;101(1):201-10.

9. Grover S, Chiyapo SP, Puri P, Narasimhamurthy M, Gaolebale BE, Tapela N, et al. Multidisciplinary Gynecologic Oncology Clinic in Botswana: A Model for Multidisciplinary Oncology Care in Low- and Middle-Income Settings. J Glob Oncol. 2017;3(5):666-70.

10. Friebel-Klingner TM, Luckett R, Bazzett-Matabele L, Ralefala TB, Monare B, Nassali MN, et al. Clinical and sociodemographic factors associated with late stage cervical cancer diagnosis in Botswana. BMC Women's Health. 2021;21(1):267.

11. Mingo AM, Panozzo CA, DiAngi YT, Smith JS, Steenhoff AP, Ramogola-Masire D, et al. Cervical Cancer Awareness and Screening in Botswana. International Journal of Gynecologic Cancer. 2012;22(4):638-44.

12. Matenge TG, Mash B. Barriers to accessing cervical cancer screening among HIV positive women in Kgatleng district, Botswana: A qualitative study. PLoS One. 2018;13(10):e0205425.

13. Rosser Jl, Njoroge B, Huchko MJ. Changing knowledge, attitudes, and behaviors regarding cervical cancer screening: The effects of an educational intervention in rural Kenya. Patient education and counseling. 2015;98(7):884-9.

14. Ama NO, Shaibu S, Burnette JD. HIV-related knowledge and practices: a cross-sectional study among adults aged 50years and above in Botswana. South African Family Practice. 2016;58(3):100-7.

15. Hsieh HF, Shannon SE. Three approaches to qualitative content analysis. Qual Health Res. 2005;15(9):1277-88.

16. Scott SE, Walter FM, Webster A, Sutton S, Emery J. The model of pathways to treatment: conceptualization and integration with existing theory. Br J Health Psychol. 2013;18(1):45-65.

17. Corbin JM, Strauss A. Grounded theory research: Procedures, canons, and evaluative criteria. Qualitative Sociology. 1990;13(1):3-21.

18. Lemp JM, De Neve JW, Bussmann H, Chen S, Manne-Goehler J, Theilmann M, et al. Lifetime Prevalence of Cervical Cancer Screening in 55 Low- and Middle-Income Countries. Jama. 2020;324(15):1532-42.

19. Ba DM, Ssentongo P, Musa J, Agbese E, Diakite B, Traore CB, et al. Prevalence and determinants of cervical cancer screening in five sub-Saharan African countries: A population-based study. Cancer Epidemiol. 2021;72:101930.

20. Ndejjo R, Mukama T, Musabyimana A, Musoke D. Uptake of Cervical Cancer Screening and Associated Factors among Women in Rural Uganda: A Cross Sectional Study. PLoS One. 2016;11(2):e0149696.

21. Sudenga SL, Rositch AF, Otieno WA, Smith JS. Knowledge, attitudes, practices, and perceived risk of cervical cancer among Kenyan women: brief report. Int J Gynecol Cancer. 2013;23(5):895-9. 
22. Cunningham MS, Skrastins E, Fitzpatrick R, Jindal P, Oneko O, Yeates K, et al. Cervical cancer screening and HPV vaccine acceptability among rural and urban women in Kilimanjaro Region, Tanzania. BMJ Open. 2015;5(3):e005828.

23. McFarland DM, Gueldner SM, Mogobe KD. Integrated Review of Barriers to Cervical Cancer Screening in Sub-Saharan Africa. J Nurs Scholarsh. 2016;48(5):490-8.

24. Lim JN, Ojo AA. Barriers to utilisation of cervical cancer screening in Sub Sahara Africa: a systematic review. Eur J Cancer Care (Engl). 2017;26(1).

25. Harries J, Scott SE, Walter FM, Mwaka AD, Moodley J. Women's appraisal, interpretation and helpseeking for possible symptoms of breast and cervical cancer in South Africa: a qualitative study. BMC Womens Health. 2020;20(1):251.

26. Bogale AL, Teklehaymanot T, Haidar Ali J, Kassie GM. Knowledge, attitude and practice of cervical cancer screening among women infected with HIV in Africa: Systematic review and meta-analysis. PLoS One. 2021;16(4):e0249960.

27. Moodley J, Constant D, Mwaka AD, Scott SE, Walter FM. Mapping awareness of breast and cervical cancer risk factors, symptoms and lay beliefs in Uganda and South Africa. PLoS One. 2020;15(10):e0240788.

28. Nyambe N, Hoover S, Pinder LF, Chibwesha CJ, Kapambwe S, Parham G, et al. Differences in Cervical Cancer Screening Knowledge and Practices by HIV Status and Geographic Location: Implication for Program Implementation in Zambia. African journal of reproductive health. 2018;22(4):92-101.

29. Barchi F, Winter SC, Ketshogile FM, Ramogola-Masire D. Adherence to screening appointments in a cervical cancer clinic serving HIV-positive women in Botswana. BMC Public Health. 2019;19(1):318.

30. Bhatia RK, Rayne S, Rate W, Bakwenabatsile L, Monare B, Anakwenze C, et al. Patient Factors Associated With Delays in Obtaining Cancer Care in Botswana. Journal of global oncology. 2018;4:113.

\section{Tables}


Table 1

Characteristics and Beliefs of Interview Participants by HIV Status

Characteristics

Living with HIV

Stage at diagnosis

IA or IB

IIA or IIB

IIIA or IIIB

Type of treatment

Curative

Age, median (IQR)

Owned cell phone

Can receive \& send text messages

Preferred language

Setswana

English

Education level

None/ Non-formal
Primary
Junior secondary
Senior secondary
Tertiary

Occupation

Housewife

Employed (by someone)

Self employed

Marital status
Total

All

participants

$(\mathrm{N}=42)$

$27(64 \%)$

$7(17 \%)$

23 (55\%)

$11(26 \%)$

$42(100 \%)$

51 (44-59)

$41(98 \%)$

40 (95\%)

13 (87\%)

$(54-67)$

$14(93 \%)$

$13(87 \%)$

35 (83\%)

$7(17 \%)$

$13(87 \%)$

$2(13 \%)$

0.06

7 (17\%)

$17(40 \%)$

$10(24 \%)$

$4(10 \%)$

$4(10 \%)$

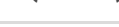

25 (60\%)

$15(36 \%)$

$2(5 \%)$

0 (0\%)

$12(80 \%)$

3 (20\%)

3 (20\%)

4 (15\%)

1 (4\%)

$3(11 \%)$

10 (37\%)

$9(33 \%)$

0.12

$13(48 \%)$

$12(44 \%)$

2 (7\%)

.

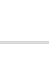




\begin{tabular}{|c|c|c|c|c|}
\hline Single & $31(74 \%)$ & $8(53 \%)$ & $23(85 \%)$ & \\
\hline Married & $8(19 \%)$ & $4(27 \%)$ & $4(15 \%)$ & \\
\hline Widowed & $3(7 \%)$ & $3(20 \%)$ & $0(0 \%)$ & \\
\hline Number of children, mean (IQR) & $3(2-4)$ & $3(2-4)$ & $3(2-4)$ & 0.88 \\
\hline Religion & & & & 1 \\
\hline None & $4(10 \%)$ & $1(7 \%)$ & $3(11 \%)$ & \\
\hline Christian & $38(90 \%)$ & $14(93 \%)$ & $24(89 \%)$ & \\
\hline Mode of transport to clinic & & & & 0.04 \\
\hline Own transport & $3(7 \%)$ & $3(20 \%)$ & $0(0 \%)$ & \\
\hline Public transport & $38(90 \%)$ & $12(80 \%)$ & $26(96 \%)$ & \\
\hline Other & $1(2 \%)$ & $0(0 \%)$ & $1(4 \%)$ & \\
\hline
\end{tabular}

\section{Screening History}

Screened at least once prior to the last

screen before cancer diagnosis

\begin{tabular}{llll} 
No & $20(48 \%)$ & $7(47 \%)$ & $13(48 \%)$ \\
\hline Yes & $10(24 \%)$ & $3(20 \%)$ & $7(26 \%)$ \\
\hline Unknown & $12(29 \%)$ & $5(33 \%)$ & $7(26 \%)$
\end{tabular}

Symptoms on last screen before cancer diagnosis $\mathrm{n}(\mathrm{col} \%)$

\begin{tabular}{lllll}
\hline Symptoms & $25(60 \%)$ & $8(53 \%)$ & $17(63 \%)$ & \\
\hline No symptoms & $6(14 \%)$ & $2(13 \%)$ & $4(15 \%)$ & \\
\hline Unknown & $11(26 \%)$ & $5(33 \%)$ & $6(22 \%)$ & \\
\hline $\begin{array}{l}\text { Days from last screen to diagnosis, } \\
\text { median (IQR) }\end{array}$ & $\begin{array}{l}52.5(15- \\
176)\end{array}$ & $52.5(15-176)$ & $47(9.5-177)$ & 0.81 \\
\hline $\begin{array}{l}\text { Days from last screen to diagnosis, } \\
\text { mean (SD) }\end{array}$ & $222(442)$ & $193(337)$ & $237(493)$ & 0.80 \\
\hline
\end{tabular}




\section{Table 2}

\section{Participant Knowledge and Beliefs}

\begin{tabular}{|c|c|c|c|c|}
\hline $\begin{array}{l}\text { Cervical Cancer Screening Awareness } \\
\text { (\% Yes) }\end{array}$ & $\begin{array}{l}\text { All } \\
(n=42)\end{array}$ & $\begin{array}{l}\text { Living } \\
\text { without } \\
\text { HIV } \\
(n=15)\end{array}$ & $\begin{array}{l}\text { Living } \\
\text { with } \\
\text { HIV } \\
(n=27)\end{array}$ & $\begin{array}{l}\mathrm{p}- \\
\text { value }\end{array}$ \\
\hline Have you ever heard of cervical cancer? & $\begin{array}{l}41 \\
(98 \%)\end{array}$ & $\begin{array}{l}14 \\
(93 \%)\end{array}$ & $\begin{array}{l}27 \\
(100 \%)\end{array}$ & 0.36 \\
\hline Have you ever heard of cervical cancer screening? & $\begin{array}{l}40 \\
(95 \%)\end{array}$ & $\begin{array}{l}14 \\
(93 \%)\end{array}$ & $\begin{array}{l}26 \\
(96 \%)\end{array}$ & 1 \\
\hline $\begin{array}{l}\text { Have you ever heard of a pap smear or a test where the } \\
\text { doctor looks at a little piece of your cervix? }\end{array}$ & $\begin{array}{l}38 \\
(90 \%)\end{array}$ & $\begin{array}{l}11 \\
(73 \%)\end{array}$ & $\begin{array}{l}27 \\
(100 \%)\end{array}$ & 0.01 \\
\hline $\begin{array}{l}\text { Have you ever heard of visual inspection with acetic acid } \\
\text { (VIA) or the vinegar test? }\end{array}$ & $\begin{array}{l}22 \\
(52 \%)\end{array}$ & $\begin{array}{l}6 \\
(40 \%)\end{array}$ & $\begin{array}{l}16 \\
(59 \%)\end{array}$ & 0.34 \\
\hline Have you heard of human papillomavirus (HPV) vaccine? & $\begin{array}{l}15 \\
(36 \%)\end{array}$ & $\begin{array}{l}4 \\
(27 \%)\end{array}$ & $\begin{array}{l}11 \\
(41 \%)\end{array}$ & 0.51 \\
\hline $\begin{array}{l}\text { Do you know anyone who has been screened for cervical } \\
\text { cancer? }\end{array}$ & $\begin{array}{l}17 \\
(40 \%)\end{array}$ & $\begin{array}{l}5 \\
(33 \%)\end{array}$ & $\begin{array}{l}12 \\
(44 \%)\end{array}$ & 0.53 \\
\hline
\end{tabular}

\section{Cervical Cancer Screening \& Risk Knowledge}

\section{(\% Correct)}

Screening tests look for changes on your cervix that indicate you are at risk for cervical cancer. $(T)$

$\begin{array}{llll}39 & 15 & 24 & 0.18 \\ (93 \%) & (100 \%) & (89 \%) & \end{array}$

Women should get screened for cervical cancer only if they have symptoms. (F)

$\begin{array}{llll}38 & 11 & 27 & 0.01 \\ (90 \%) & (73 \%) & (100 \%) & \end{array}$

If a woman has abnormal vaginal bleeding...she should see a medical provider to get screened. $(\mathrm{T})$

42 15

$(100 \%) \quad(100 \%) \quad(100 \%)$

Cervical cancer can be prevented. $(\mathrm{T})$ 40

Screening tests can help prevent cervical cancer. $(T)$

$\begin{array}{lll}40 & 15 & 25 \\ (95 \%) & (100 \%) & (93 \%)\end{array}$

There is no treatment for cervical cancer. $(\mathrm{F})$

29

10

$(67 \%)$

19

(70\%)

Family planning increases a woman's risk of cervical cancer.

(F)

19

Having HIV increases a woman's risk of cervical cancer. $(T)$

Only HIV+ women are at risk of getting cervical cancer. (F)

\begin{tabular}{ll}
31 & 9 \\
& $(74 \%)$ \\
\hline
\end{tabular}

$\begin{array}{ll}4 & 15 \\ (27 \%) & (56 \%)\end{array}$

$\begin{array}{ll}9 & 22 \\ (60 \%) & (81 \%)\end{array}$




\begin{tabular}{|c|c|c|c|c|}
\hline & $(79 \%)$ & $(73 \%)$ & $(81 \%)$ & \\
\hline $\begin{array}{l}\text { Women can lower their risk of cervical cancer by washing } \\
\text { inside their vagina. }(\mathrm{F})\end{array}$ & $\begin{array}{l}22 \\
(52 \%)\end{array}$ & $\begin{array}{l}4 \\
(27 \%)\end{array}$ & $\begin{array}{l}18 \\
(67 \%)\end{array}$ & 0.01 \\
\hline $\begin{array}{l}\text { Women can lower their risk of cervical cancer by getting a } \\
\text { screening test. }(T)\end{array}$ & $\begin{array}{l}41 \\
(98 \%)\end{array}$ & $\begin{array}{l}15 \\
(100 \%)\end{array}$ & $\begin{array}{l}26 \\
(96 \%)\end{array}$ & 0.45 \\
\hline $\begin{array}{l}\text { Women can do nothing to prevent cervical cancer because it } \\
\text { is fate or God's will. (F) }\end{array}$ & $\begin{array}{l}31 \\
(74 \%)\end{array}$ & $\begin{array}{l}11 \\
(73 \%)\end{array}$ & $\begin{array}{l}20 \\
(74 \%)\end{array}$ & 0.96 \\
\hline \multicolumn{5}{|l|}{ HPV-specific Knowledge (\% Correct) } \\
\hline HPV is an infection that can cause cervical cancer. $(T)$ & $\begin{array}{l}26 \\
(62 \%)\end{array}$ & $\begin{array}{l}10 \\
(67 \%)\end{array}$ & $\begin{array}{l}16 \\
(59 \%)\end{array}$ & 0.64 \\
\hline $\begin{array}{l}\text { HPV is spread by close contact between humans like during } \\
\text { sexual intercourse. }(T)\end{array}$ & $\begin{array}{l}24 \\
(57 \%)\end{array}$ & 8 & $\begin{array}{l}16 \\
(59 \%)\end{array}$ & 0.71 \\
\hline $\begin{array}{l}\text { People with an HPV infection will always have vaginal } \\
\text { symptoms. (F) }\end{array}$ & $2(5 \%)$ & $1(7 \%)$ & $1(4 \%)$ & 0.67 \\
\hline \multicolumn{5}{|l|}{ HIV Awareness } \\
\hline $\begin{array}{l}\text { Have you heard about the disease known as HIV and AIDS? } \\
(Y)\end{array}$ & $\begin{array}{l}42 \\
(100 \%)\end{array}$ & $\begin{array}{l}15 \\
(100 \%)\end{array}$ & $\begin{array}{l}27 \\
(100 \%)\end{array}$ & \\
\hline Is HIV and AIDS a communicable disease? (Y) & $\begin{array}{l}41 \\
(98 \%)\end{array}$ & $\begin{array}{l}15 \\
(100 \%)\end{array}$ & $\begin{array}{l}26 \\
(96 \%)\end{array}$ & 1 \\
\hline Is HIV the infection that causes AIDS? $(\mathrm{Y})$ & $\begin{array}{l}41 \\
(98 \%)\end{array}$ & $\begin{array}{l}15 \\
(100 \%)\end{array}$ & $\begin{array}{l}26 \\
(96 \%)\end{array}$ & 1 \\
\hline Does AIDS affect the immune system? (Y) & $\begin{array}{l}42 \\
(100 \%)\end{array}$ & $\begin{array}{l}15 \\
(100 \%)\end{array}$ & $\begin{array}{l}27 \\
(100 \%)\end{array}$ & - \\
\hline \multicolumn{5}{|l|}{ HIV Transmission Knowledge (\% Correct) } \\
\hline By sexual intercourse $(Y)$ & $\begin{array}{l}42 \\
(100 \%)\end{array}$ & $\begin{array}{l}15 \\
(100 \%)\end{array}$ & 27 & - \\
\hline Through witchcraft or other supernatural means $(\mathrm{N})$ & $\begin{array}{l}40 \\
(95 \%)\end{array}$ & $\begin{array}{l}14 \\
(93 \%)\end{array}$ & $\begin{array}{l}26 \\
(96 \%)\end{array}$ & 0.67 \\
\hline From mother to child $(Y)$ & $\begin{array}{l}41 \\
(98 \%)\end{array}$ & $\begin{array}{l}15 \\
(100 \%)\end{array}$ & $\begin{array}{l}26 \\
(96 \%)\end{array}$ & 0.45 \\
\hline By sharing needle or syringe $(\mathrm{Y})$ & $\begin{array}{l}40 \\
(95 \%)\end{array}$ & $\begin{array}{l}14 \\
(93 \%)\end{array}$ & $\begin{array}{l}26 \\
(96 \%)\end{array}$ & 0.67 \\
\hline By blood transfusion $(\mathrm{Y})$ & $\begin{array}{l}35 \\
(83 \%)\end{array}$ & $\begin{array}{l}11 \\
(73 \%)\end{array}$ & $\begin{array}{l}24 \\
(89 \%)\end{array}$ & 0.19 \\
\hline By shaking hands $(\mathrm{N})$ & $\begin{array}{l}36 \\
(86 \%)\end{array}$ & $\begin{array}{l}13 \\
(87 \%)\end{array}$ & $\begin{array}{l}23 \\
(85 \%)\end{array}$ & 0.90 \\
\hline $\begin{array}{l}\text { By eating from same plate or drinking from same glass as a } \\
\text { person with HIV }(\mathrm{N})\end{array}$ & $\begin{array}{l}37 \\
(88 \%)\end{array}$ & $\begin{array}{l}13 \\
(87 \%)\end{array}$ & $\begin{array}{l}24 \\
(89 \%)\end{array}$ & 0.83 \\
\hline
\end{tabular}


By wearing the same clothes as a person with HIV (N)

$\begin{array}{lll}38 & 13 & 25 \\ (90 \%) & (87 \%) & (93 \%)\end{array}$

0.53

By a bite from a mosquito or other insect $(\mathrm{N})$

13

$(31 \%)$

3

10

0.25

Through contact with a doctor, dentist, or other health care professional $(\mathrm{N})$

32

$(76 \%)$

$(20 \%)$

$(37 \%)$

Through a curse $(\mathrm{N})$

30

$(71 \%)$

As a punishment from $\mathrm{God}(\mathrm{N})$

35

$(83 \%)$

9

$(60 \%)$

23

0.07

$(85 \%)$

0.84

$\begin{array}{ll}11 & 19 \\ (73 \%) & (70 \%)\end{array}$

14

$(93 \%)$

21

$(78 \%)$

0.19

\section{HIV Prevention Knowledge (\% Correct)}

By not sharing needles, syringes, or apparatus to inject drugs, vitamins, hormones, steroids, or medicine $(Y)$

39

$(93 \%)$

HIV can be prevented by using condoms properly during
sexual intercourse $(Y)$

HIV transmission can be avoided by remaining faithful to a single partner $(\mathrm{Y})$

HIV transmission can be avoided by having a blood test before marriage $(\mathrm{N})$

HIV can be prevented by avoiding blood transfusions (Y)

HIV can be prevented by abstinence (no sex at all) $(Y)$

HIV can be prevented by no casual sex $(Y)$

HIV can be prevented by no commercial sex (Y)

HIV can be prevented by having fewer partners $(Y)$
19

$(45 \%)$

38 (90\%)

42

(100\%)

42 (100\%)

42

$(100 \%)$

14

$(93 \%)$

25

(93\%)

0.93

$41 \quad 15$

15 (100\%)

26

(96\%)

0.45

$\begin{array}{lll}42 & 15 & 27 \\ (100 \%) & (100 \%) & (100 \%)\end{array}$

$0(0 \%) \quad 0(0 \%) \quad 0(0 \%) \quad$ -

\section{Total \% Correct of Factors (higher= more correct)}

Cervical Cancer Screening Factors (0-12), Mean (SD)

9.6

8.9

(1.9)

10.0

(1.5)

HIV Transmission Factors (0-12), Mean (SD)

10.0

(1.5)

9.7

(1.5)

10.1

(1.5)

HIV Prevention Factors (0-9), Mean (SD)
7.3

$(0.8)$
7.5

$(0.5)$
11

(41\%)

0.43

0.12
$(85 \%)$

27

(100\%)

(100\%)

27

(100\%) 


\section{Table 3}

\section{Participant Thematic Quotes}

\section{Domain/Themes MPT Phase \\ Exemplar Quotes (in addition to those listed in the text)}

Limited awareness of

screening as

prevention

Appraisal

Higher awareness.

When you test [the] first time and you are negative it does not mean you it will never be there. You have to keep on going back to test for whether it is there or it is not (Early-50s, PLWH).

\section{Lower awareness:}

According to what I heard; unprotected sex can cause cervical cancer. To prevent it you can consult with the doctors so they can identify whether you have the illness or not and give you treatment such as chemotherapy or radiation (Late-40s, PLWH).

Limited knowledge about HPV
Appraisal

Yes ma'am. I am disappointed to say this. I do not understand about the [HPV] virus...I have not come to know of it (Early-50s, PLWH).

What I have heard is that cervical cancer can be caused by having sex at a younger age. . .Cervical cancer can be prevented by refraining from sex while still young. . .I have no idea what causes HPV and how it can be prevented (Early-50s, PLWH).

I would not want to lie to you and say I have heard anything [about what causes cervical cancer]. What I know is while listening to people with cervical cancer, us women, most people thought it was witchcraft (Late-60s, PLWH).

High HIV-related Appraisal awareness
With HIV I it is an issue I could say is like a national anthem we always hear about on the radio. Every time even on the radio we are taught about it. (Late 60s, PLWH)

HIV is transmitted through unprotected sexual intercourse, having multiple sexual partners, and getting into marriages without getting tested...t is desirable that when realize that children are starting to mature we teach them about HIV transmission and that it can be prevented through protected sex and going for testing. Now we can prevent it through being keen on testing and protecting ourselves. (Early-50s, PLWH)

I have heard that it is caused by having multiple sex partners, sharing needles with HIV positive individuals...It can be prevented by sticking to one partner and avoiding sharing needles. (Early40s, PLWH) 
Yes, ma'am it can be prevented by not having unprotected sexual intercourse. When you have sex you have to use condoms. (early40s, PLWH)

Cancer fear and fatalism
Appraisal/

Help-

Seeking

Help-

seeking

I am not someone who visits hospitals regularly [and] hear people speaking ill of [hospital]. As if to say when you go to [the hospital] you are lost. (Late-60s, PLWH)

[After hearing my diagnosis] my emotions became low, and I would ask myself what the way forward is. What is going to happen in future? Am I going to find that it has become worse? Or at what stage is it going to be in future? (Early-30s, PLWH)

After I was told the results, I became emotionally mixed up. I lost faith. I just saw death in me because we are used to knowing that when you hear that someone has cancer you know that they are going to die. This is what I thought of until I received treatment... that is when I had hope (Late 40s)

Structural and individual barriers to seeking care
Help

Seeking

I do not know how to explain those reasons, but I kept on postponing. I couldn't get leave days from my employer because she complained of my absence in the workplace. In one instance I lost my job because I had to go for check-ups and the employer could not keep up with it Late-40s, PLWH)

Diagnostic

It is difficult [to get healthcare services] because I have to use public transport. I see that I just have to make a decision and appeal to my children... It is slightly difficult because I have to first tell my children that this is when [my appointment is] and then they would then rush to assist (Early-70s,)

Delays in receipt Diagnostic of results

But I had tested because I was unwell and was not feeling well. My results were unavailable. I then remained for a while. I continued to feel that my health was deteriorating (Early-60s)

I had spent a long time waiting for results because I had spent years testing for this virus trying to find out what it is whether it is AIDS or it is the cancer... They tested me and the papers disappeared. The result had also disappeared. This and that... I was not receiving the results [of the screening tests]. (Late-60s, $\mathrm{PLWOH}$ )

Social and religious sources of support
All phases

I was so scared thinking that was the end of my life...[but] I received very great support from my family and the health providers. (Early-50s, PLWH)
"I was sad but soon told myself, "Nowadays it is better it is no longer like the old days." ... "Nowadays the doctors are here." My emotions then became better. I became faithful and thought of God. I thought of God that God is here. When they were treating me and put me where they put me, I will accept. But I was saying this to myself while also praying (Late-60s) 
them.... I just go and receive consultation...Because I do not hide. (Late-50s, PLWOH)

"It is very easy [to seek health services] ... My health comes first, and it is my main concern" (Late-60s).

Abbreviations.

MPT: Model of Pathways to Treatment

PLWH: Person living with HIV

PLWOH: Person living without HIV 